\title{
Funcionamiento intertextual entre nuevas propuestas teatrales chilenas y publicidad, tanto televisiva como piezas de diseño gráfico
}

Erika CORTES

Teóricos contemporáneos como Calabrese, Lyotard, Landow, entre otros, han descrito a la cultura audiovisual postmoderna como una forma de funcionamiento que implica un descentramiento de los géneros, una fragmentación de los objetos culturales (que pondrá énfasis en los detalles, en los fractales descritos por Mandelbrot en la "nueva geometría de la naturaleza"), y una interrelación gradual polidialógica de diferentes textos muchas veces contradictorios (rigiéndose por la "matemática del caos propuesta por Thom").

El saber acumulado de este fenómeno pone énfasis en la pérdida de la noción de texto cultural cerrado y autónomo, planteándose nuevas formas de generación y lectura, con relaciones intertextuales e hipertextuales entre diferentes medios.

Esta nueva realidad emergente coincide con las formas de funcionamiento clásicas: cerradas, autónomas, coherentes, y totalizadoras.

El sentido de este artículo es sintetizar una investigación que pretende dar cuenta de estas nuevas formas de funcionamiento cultural en el Chile de Hoy: concretamente describir las relaciones entre las nuevas propuestas teatrales chilenas, la publicidad (espots publicitarios), y el diseño gráfico de las portadas de revistas, desde el punto de vista de su sintaxis visual.

Fenomenológicamente se detecta que las nuevas propuestas teatrales chilenas tienen un público juvenil. El sentido de este artículo no es explicar este tipo de fenómeno, sino que contribuir a investigaciones más profundas sobre la materia: ¿qué 


\section{COMUNICACION y MEDIOS}

tienen en común este nuevo tipo de propuestas teatrales, con los otros textos propuestos por los medios masivos como la portadas de revistas y los espots publicitarios?

Para poder entender el fenómeno sociosemiótico de las nuevas propuestas teatrales se necesita previamente, a través de estudios semióticos exploratorios, saber que tipo de imágenes nos plantea estas nuevas propuestas, y que relación tienen con otros textos culturales.

Hablo de nuevas propuestas teatrales, cabe preguntarse ¡con qué criterios se define lo que se entiende por nuevas propuestas?, o más bien, ¿con qué criterio se delimita lo que es nuevas propuestas?

El criterio ha sido empírico: se estudió originariamente tres obras presentadas en el Festival de Nuevas Tendencias Teatrales, organizado por la Universidad de Chile en 1998. Se elaboró un modelo semiótico interpretativo de ellas, que se aplicó a las otras obras dejadas sin analizar, de ese festival, buscando la validación de dicho modelo interpretativo, a través de lo que la semiótica de Greimas llama satuación.

Una vez validado el modelo interpretativo, como descriptor de dicha nueva realidad emergente, se aplicó a otras obras teatrales del mismo período, en función de tener un marco más amplio sobre lo que se había delimitado como objeto real de estudio: allí se estudiaron seis obras más, susceptibles de ser partícipes de lo que se describe, en esta investigación, como nuevas propuestas teatrales.

De allí, que el corpus (conjunto de textos a investigar) esté constituido, en definitiva por nueve obras, las que se correlacionarán a espots y portadas de revistas.

Luego, la presente comunicación se circunscribe a exponer los hallazgos que exploratoriamente la investigación ha establecido entre publicidad, diseño y teatro. En un corpus formado, entonces, por nueve obras dadas durante enero y febrero del $98 \mathrm{y}$ la publicidad televisiva de los canales de la televisión abierta durante una semana y las portadas de las revistas, de la misma época.

Esta investigación que sintetizo mezcla lo cuantitativo con lo cualitativo.

La investigación estableció descriptores de la cultura dásicay de la postmoderna a través del uso de pares de oposiciones que fueron construídos a partir de varios autores (Calabrese respecto a las características del texto postmoderno manifestado en la Era

$90 \mid$ Neobarroca, Kristeva respecto al rol de lo referencial y lo onírico e intertextualidad, Del Villar con respecto al rol asignado a la música.)

El análisis se situó no a nivel de los contenidos ni de la estructura narrativa sino que de las formas de funcionamiento visual que tanto el teatro como la publicidad y el diseño adscriben. Los protocolos descriptivos fueron los siguientes: 
1. Texto como productividad y engendramiento. Concepto que encontramos en la obra de Kristeva, en tanto que intertextualidad, y en la noción de Calabrese de descentramiento de los géneros.

En relación a la intertextualidad (Kristeva 1981), nos encontramos frente a un texto que nos remite a otros textos.

Al mismo tiempo, este remitirse a otros textos va junto, en los textos estudiados, con transgredir las estructuras estables de los géneros, incluyendo o ligando otros géneros. Esto es, en este caso, estaríamos también ante un descen-tramiento de los géneros, según Calabrese, (Calabrese, 1994), así la percepción del discurso y de los objetos representados en el discurso se hace vaga, indefinida, indistinta. (Calabrese 1994: 179).

2. El rol asignado a la música. Este nivel de análisis retroalimenta la noción de intertextualidad, pues permite describir si la estética planteada en la puesta en escena, se acerca a la de un Video Clip dónde la música modaliza a la puesta en escena, o sí es un simple atributo de la imagen. Lo mismo ocurre en el Espot Publicitario.

3. El rol de la imagen. La luz, las diapositivas, surgen como un personaje más, retroalimentándose la noción de intertextualidad, ya que la proyección de estas imágenes le permite al espectador situarse en otro texto independiente y después establecer la relación con el principal, insertando elementos plásticos en la imagen.

4. Vago / preciso. Nociones propuestas por Calabrese en La Era Neobarroca, enfatizando el concepto de descentramiento del género, no existe una precisión en relación al tópico presentado. Sele da cabida a la experimentación, a la improvisación, lo que contextualiza a la puesta en una recreación con características de vaguedad.

5. Fragmentación / globalización. Nociones propuestas por Calabrese. En estas propuestas visuales no prima la globalidad (totalidad); se destaca la fragmentación (porción o fracción).

Se estructura el texto en función del detalle, el fragmento y cada fragmento compone la arquitectura del texto total, conectándose cada uno y dándole coherencia al todo.

6. Metamorfosis de los personajes. Se mutan unos con otros.

7. Textos contradictorios / coherentes. Existe una clara oposición entre lo contradictorio y lo coherente que se ve reflejado en estas propuestas visuales. A las formas estables, ordenadas, regulares, simétricas, se van sustituyendo formas inestables, desordenádas, irregulares, asimétricas. (Calabrese, 1994 : 197).

8. Simple / complejo. Al existir un descentramiento del género, una 
vaguedad, una fragmentación en estas propuestas escénicas, se nos revelan textos complejos totalmente opuestos a textos simples, por lo mismo requieren de un lector activo que participe en la interpretación de cada uno de estos textos.

9. Onírico / referencial. Noción planteada por autores como Lyotard (dispositivos pulsionales / referencia lo real) y Kristeva (lo imaginario / lo simbólico). Esta categoría se inserta en una cultura de la imagen cada vez menos referencial, cada vez más alejada de representar objetos visibles.

Estos protocolos descriptivos se aplicaron tanto a la publicidad, el diseño de portadas como a las obras de teatro.

El diseño de la investigación fue cualitativo desde el punto de vista de asignarle al texto un lugar en las categorías planteadas. Se estableció en el corpus de nueve obras la recurrencia de cada una de las categorías, estableciéndose su \% estadístico. El \% estadístico nos permitió captar el uso de algunos de los elementos dela sintaxis en las obras permitiéndonos tener un mapa de las categorías analíícas empleadas, lo que nos permitió tener un criterio de comparación.

Asísi el \% total de obras eran 9, el \% total de las piezas televisivas estudiadas estaba constituido por Televisión Nacional de Chile cuyo rating tiene 38,9\%; Universidad Católica de Chile con un rating que llega a los 32,8\%; Rock Pop Televisión cìya audiencia máxima es un 3\%; la Red Televisión con un $11,3 \%$, Chilevisión con un 9,3\% y Megavisión con un 24\%; según los estudios televisivos de la empresa Time.

Las obras teatrales estudiadas fueron : La voluntad de morir, Informe para una Academia, La Metamorfosis, estas tres de la Compañía La Puerta, dirigida por Luis Ureta; Vogue: creación, dirección e interpretación de Francisco Copello; Casanova, cuerpo ,amor, deseo, muerte: Textos Fernando Arrabal, dirección Andrés Hernández, Compañía teatro Karadagian; La reforma del entendimiento: autor Benjamín Galemiri, dirección Cristián Quezada; Módulo 7: de la Compañía Anderblú, dirección Rodrigo Achondo; Chile Fértil Provincia: textos de Gloria Moreno, Arturo Latrop y adaptación del libro Operación Albania, dirigida por Ramón Griffero; Sueño de una Noche de Verano: de William Shakespeare de la Compañía Calibán y dirigida por Andrés Pérez.

Las piezas gráficas analizadas fueron : quince números de las revistas : a)

92 Diseño; Cosas; Paula; Ercilla; Ya (Revista de El Mercurio); Estilo de Vida y Decoración; Rocinante; TVNovelas.

\section{Conclusiones propuestas teatrales}

Las propuestas estudiadas se diferencian a su vez por el goce de los detalles y 
tiene un mismo acceso a las portadas.

\section{La descripción de los tres medios dio el siguiente resultado:}

1. La música: Aparece como atributo de la imagen, en la mayoría de los espots publicitarios; la excepción son aquellos que toman la forma de un clip, esto no ocurre en el teatro, dónde más de la mitad de las obras del corpus tienen fragmentos dónde se modaliza la puesta en escena por la música: La voluntad de morir, Informe para una academia, La metamorfosis, Vogue, Casanova, cuerpo, amor, deseo, muerte. Lo que significa que respecto a este punto hay una intertextualidad del video clip, más que de la publicidad.

2. Rol asignado a la luz: La luz como modalizador de la imagen se da en una minoría de los espots analizados del corpus: ejemplo Queso Colún, Energizer, etc. Sin embargo en el teatro la luz se constituye como un actante, teniendo ella un rol narrativo: Vogue, Informe para una academia, La voluntad de morir, La metamorfosis; esto es en la mayoría de la obras analizadas. Lo mismo ocurre en el diseño de las portadas de las revistas, dónde en un $75 \%$ la luz tiene un rol protagónico; por lo que se establece una ligazón entre teatro y diseño gráfico de portadas. Esto es, la presencia en el diseño de la luz como actante modalizador está presente en las nuevas tendencias teatrales chilenas, más que en la publicidad misma.

3. Rol de la intertextualidad, en términos de descentramiento de género: Tenemos que 61 casos del corpus de espots publicitarios presentan dicho descentramiento y 61 no lo tienen, lo que significa que de la totalidad de espots analizados en el corpus la mitad presenta la presencia de una intertextualidad de este tipo.

Si analizamos la frecuencia de espot al interior del corpus, nos encontramos que Televisión Nacional y Televisión de la Universidad Católica, los canales más vistos según las encuestas, tienen un $89 \%$ de espots con presencia de un descentramiento de géneros, En Rock and Pop Televisión, el 60\% de los espots más repetidos implican dicho descentramiento del género. En la Red Televisión, el $80 \%$ de los espot más repetidos, implican dicho descentramiento del género. Esto significa que en los canales de televisión abiertos con menos público también la presencia de mezcla de génerose intertextualidad es preponderante.

Esto tiene una correlación directa con las obras teatrales analizadas dónde la intertextualidad es preponderante, excepto la obra Módulo 7, que tiene una estructura fundamentalmente narrativa.

Respecto al diseño de las portadas hay una estabilidad del género en un 
$67,5 \%$ y un descentramiento en un $32,5 \%$. Esto implica que del punto de vista mayoritario no hay una correlación entre portadas y nuevas tendencias teatrales. Sin embargo por ser este descentramiento un 32,5 en portadas, ello implica que en alguna medida hay una relación entre teatro y portadas, aunque no se correspondan directamente los porcentajes.

4. Vago / preciso: Del corpus de espotsanalizados podemos decir que es preponderante la explicitación clara del atributo que se pretende ligar al producto. La idea de un posicionamiento único, distintivo y claro es dominante en la publicidad televisiva chilena, siguiendo los delineamientos planteados por las teorías clásicas de la publicidad: Jack Trout, Al Ries, Stivken, Martineau, Bernwack, entre otros. Lo vago e impreciso sólo se configura en un $22 \%$ del corpus analizado de espot.

Esto no tiene un correlato con el corpus de obras de teatro analizadas, dónde sólo un 30\% tienen un delineamiento preciso.

Si en el teatro la inmensa mayoría de las obras se insertan dentre de la imprecisión (70\%) y sólo un 30\% de precisión, en las portadas de revistas nos encontramos con una relación similar a las de espots, un $20 \%$ de ellas son vagas y un $80 \%$ precisas.

5. Dinámico / estático: Lo predominante en la publicidad es el dinamismo, el paso de una secuencia a la otra, el mantenimiento de una sola escena se da sólo en un 16,4\% del corpus analizado.

Lo mismo ocurre en el teatro, pues la categoría estaticidad se da en un $22 \%$ de las obras; esto es, sólo dos de las obras analizadas se dan en un mismo espacio : La reforma del entendimiento e Informe para una academia.

Si en las nuevas tendencias teatrales y en la publicidad predominan el pasar de un espacio a otro (Lo que hemos denominado dinámico), habiendo una correlación directa entre publicidad y teatro de vanguardia, en el caso de las portadas de diseño nos encontramos con una proporción bastante similar de ambas opciones: dinámico $49,5 \%$, estático $50,5 \%$. Por lo que hay una relación estrecha entre publicidad y nuevas tendencias teatrales y las portadas de revistas sólo contribuyen a la opción dinámico en un 49,55.

6. Referencial / onírico: Un 45\% de los espots son oníricos. Analizando

$96 \mid$ los espots según su frecuencia de repetición, vemos que el 60\% de los espots más vistos en Televisión Nacional son oníricos, lo mismo ocurre en Televisión Universidad Católica, pues sólo un $40 \%$ tienen un contenido real. En Chilevisión sólo un $35 \%$ de los espots analizados como más frecuentes tienen un contenido onírico y en Rock and Pop un $40 \%$ tiene un contenido real. 
Si bien es cierto que la oferta total de espotses aproximadamente un $50 \%$ sobre $50 \%$ entre lo onírico y lo real, desde el punto de vista de su repetición, prima el contenido onírico; lo que tiene un correlato con las obras de teatro estudiadas, dónde un 30\% de las obras son reales: documentales (Ramón Griffero), o cuadros de vida cotidiana: La reforma del entendimiento y Módulo 7.

Respecto a las portadas de las revistas. Ellas son en un $55 \%$ oníricas, por lo que ellas se correlacionan con el tratamiento onírico tanto del teatro como en la publicidad.

7. El uso de fragmentos, la primacía de las partes por sobre el todo: Tenemos que 75 espots tienen una construcción fragmental, lo que corresponde al $62 \%$ del total del corpus analizado.

Ello está en correspondencia con La voluntad de morir, La metamorfosis, Informe para una academia, Vogue, Casanova, cuerpo, amor, deseo, muerte, Sueño de una noche de verano. A diferencia de La reforma del entendimiento, Módulo 7 y Chile fértil provincia, dónde predomina el concepto de unidad, por sobre la parte, constituyendo un $33 \%$ de las obras, lo que se correlaciona con el porcentaje de estructura coherente unificada que vemos en la publicidad y el $38 \%$ de los espots.

La correlación descubierta entre publicidad y nuevas tendencias teatrales también implica a las portadas de diseño gráfico, pues lo fragmentario ocupan en ella un $56,6 \%$ y lóglobalizado un $43,4 \%$.

8. Estabilidad de los personajes: Se presenta casi en el $99 \%$ de los personajes de la publicidad televisiva chilena. En el corpus dè teatro los personajes no son estables en: La voluntad de mori, Informe para una academia, Vogue, Casanova, cuerpo, amor, deseo, muerte, Chile fértil provincia. Siendo sólo estable en La Metamorfosis, Sueño de una noche de verano y Módulo 7, esto es los personajes son estables en un $33 \%$ del corpus estudiado e inestables en un $66 \%$, lo que no tiene correlato con la publicidad.

Respecto a las portadas de revistas ellas tienen personajes estables en un $88,3 \%$ e inestables en un $11,7 \%$ lo que retroalimenta la idea de que con respecto a este ítem no hay correlación entre publicidad, portadas de revistas y nuevas tendencias teatrales.

9. Contradictorio / coherente: Lo contradictorio aparece con un número de 22 casos en el corpus de espots analizados lo que equivale a un $18 \%$ de la totalidad; lo que significa que en la televisión publicitaria chilena predomina lo coherente por sobre lo contradictorio.

En el corpus de obras estudiado son incoherentes: Casanova, cuerpo, amor, 
deseo, muerte, Vogue, La voluntad de morir, Informe para una academia; esto es un $44 \%$, lo que significa que en publicidad no se hace uso de este principio de funcionamiento cultural.

El estudio del diseño de portadas de revistas establece que el $82,55 \%$ son coherentes y contradictorias en un $17,45 \%$. Esto implica que en la sociedad chilena los medios masivos publicidad y portadas de revistas no usan una argumentación contradictoria; pero en las nuevas tendencias teatrales si es usado, aunque no mayoritariamente, reiteramos un $44 \%$.

10. Simple / complejo: En relación a la categoría simple / complejo, el $71 \%$ del corpus de espot estudiado tiene un delineamiento simple.

Esto es diferente a las formas de expresión teatral más utilizadas. Son simples :La reforma del entendimiento y Módulo 7; esto es sólo un 22\% del corpus de obras teatrales estudiadas.

En las portadas de las revistas tenemos que un $67,5 \%$ son simples y complejas en un $32,5 \%$. Por lo que hay un comportamiento común respecto a su sintaxis visual, tanto en la publicidad ( $71 \%$ ) como en las revistas (67\%). Esto es, los consumidores de la cultura audiovisual son expuestos a estructuras visuales, simples en su mayoría. La agenda de los medios, entendida como temáticas, formas de argumentación visuales a los que todos los sujetos están expuestos, tiene una misma manifestación.

Debe tenerse en cuenta que la categoría complejo no está ausente en la agenda setting. En la publicidad el $29 \%$ de los espots son complejos y en las portadas de revistas un $32,5 \%$.

Esto es diferente en las obras teatrales, dónde se invierte la relación, sólo un $22 \%$ del corpus son simples y un $78 \%$ son complejas. 


\section{Bibliográfía}

BAUDRILLARD, Y OTROS. (1996): Videoculturas de fin de siglo, Madrid, Ed. Cátedra.

BOBES NAVES, M. Del C. (1998): Estudios de semiología del teatro, Madrid, Aceña Editorial.

CALABRESE, O. (1994): La era neobarroca, Madrid, Edit. Cátedra.

CENTRO NACIONAL DE NUEVAS TENDENCIAS ESCÉNICAS: La escritura teatral a debate, Ponencias y Coloquios del encuentro de autores teatrales, 1985, Madrid, Ministerio de Cultura Dirección general de música y teatro.

CORTES, E. (1996): El escenario: ¿Un símbolo postmodernista? En: Estudios de literatura chilena e hispanoamericana contemporánea, Editorial Universidad de los lagos, VIII Seminario Internacional de Estudios Literarios. Universidad de los Lagos. Sociedad Chilena de Estudios Literarios (Sochel) Osorno, 23 al 26 de Noviembre de 1994.

CORTÉS, E (1996): Funcionalidad y Aplicaciones de la Semiótica Teatral en Revista Chilena de Semiótica $n^{\circ} 1$. Ediciones Departamento de Ciencias y Técnicas de la Comunicación. Universidad de Chile. Internet : (http://rehue.csociales.uchile.cl)

CORTÉS, E (1997). El Gran Circo Teatro: Una nueva forma de expresión en Revista Chilena de Semiótica $n^{\circ} 3$. Ediciones Departamento de Investigaciones Mediáticas y de la Comunicación, y Escuela de Periodismo, Universidad de Chile. Internet : (tttp://rehue.csociales.uchile.cl)

DEL VILLAR, R. (1997):Trayectos en Semiótica Fílmico Televisiva, Santiago,.Edit.Dolmen.

ELAM, KEIR (1988): Semiótica del Testro, Bologna:II Mulino.

GREIMAS, A. J. (1966): "Sémantique structurale", Paris, Ed. Larousse. U GUTIÉRREZ, FABIÁN: Teoría y Praxis de Semiótica Teatral, Universidad de Valladolid.

KRISTEVA, J (1982): Semiótica I y Il .Madrid, Ed. Fundamento.

KOWZAN, TADEUSZ (1992): Sémiologie du Théatre, Paris, Ed. Nathan.

MANDELBROT, BENOIT (1997): "La geometría fractal", Barcelona, Ed. Tusquets.

RUFFINI, FRANCO (1978): Semiótica del Testo L Esempio Teatro, Roma, Bulzoni. Editore.

THOM, RENÉ (1987): Estabilidad Estructural y Morfogénesis", Barcelona, Ed. Gedisa.

UBERSFELD, A (1993): Semiótica Teatral,Madrid, Edit. Cátedra.

UBERSFELD, A(1996): Lire le Théatre II .L École du spectateur, Paris, Editions du Seuil.

UBERSFELD, A (1996): Lire le Théatre III. Le dialogue de theatre, Paris, Editions du Seuil.

UBERSFELD, A (1996): Les Termes Clés de Lanalyse du Théatre, Paris, Editions du Seuil. 
